\title{
Using climate information for drought planning
}

\author{
Taryn Finnessey ${ }^{1, *}$, Michael Hayes ${ }^{2}$, Jeff Lukas ${ }^{3}$, Mark Svoboda ${ }^{2}$ \\ ${ }^{1}$ Colorado Water Conservation Board, Department of Natural Resources, 1313 Sherman St., Rm 721, Denver, CO 80203, USA \\ ${ }^{2}$ National Drought Mitigation Center, University of Nebraska-Lincoln, 3310 Holdrege Street, Lincoln, NE 68583-0988, USA \\ ${ }^{3}$ Cooperative Institute for Research in Environmental Sciences, Western Water Assessment, University of Colorado, Boulder, \\ CO 80304, USA
}

\begin{abstract}
Historically, drought has been responded to rather than prepared for, yet studies have illustrated that proactive investment in drought risk management reduces impacts and overall response costs. One key element of preparedness is the use of sufficient climate information for monitoring, forecasting, and tracking long-term trends. In the face of a changing climate and increasing variability, these types of data are even more critical for planning and overall resiliency. The systematic use of these data to inform the drought planning component of drought risk management is a relatively recent development. Actionable science has direct applicability for planning and decision-making, and allows for an iterative process between scientists and end users that can build long-term drought resiliency. The article will describe how planners in Colorado are increasingly relying on climate data, ranging from paleoclimatological records to experimental seasonal forecasts, to guide their long-term drought preparedness and climate change adaptation efforts. This information can then be used to inform broader policy and planning efforts, unifying the scientific basis across multiple processes. In addition, the Integrated Drought Management Programme (IDMP), with the World Meteorological Organization (WMO) and the Global Water Partnership (GWP) as co-leads, promotes national policies encouraging proactive risk management, and provides a platform for sharing the lessons learned by the planners, policy makers, and scientists around the world. Data-driven decision-making using climate information can help depoliticize actions and increase overall resiliency and response in times of drought, which will be increasingly important as the world warms.
\end{abstract}

KEY WORDS: Drought planning $\cdot$ Preparedness $\cdot$ Risk management $\cdot$ Resiliency

\section{OVERVIEW OF DROUGHT RISK MANAGEMENT}

Recent drought events around the world have demonstrated that droughts are normal, yet costly, natural disasters in most climates. Examples include the California drought in the United States of America, which cost a roughly estimated US\$5 billion in agricultural impacts over consecutive years in 2014 to 2015 , and illustrates the potentially huge economic impacts resulting from droughts in the developed world (Howitt et al. 2014, 2015). In Brazil, a recent multiple-year drought threatened water supplies for

\footnotetext{
${ }^{*}$ Corresponding author: taryn.finnessey@state.co.us
}

the residents of Sao Paulo, the ninth-largest metropolitan area in the world and the largest in South America. The 2011 drought across the Greater Horn of Africa region confirmed that droughts can cause famines and human mortality. Meanwhile, the 2006 to 2011 drought in the Middle East is indirectly linked to the recent disruptions and chaos across northern Africa and the Middle East, contributing to the current unrest in Syria and the migration crisis facing the European continent (Gleick 2014).

These droughts are occurring within the context of a world facing multiple global risks, including those involving water and food crises, climate change, and

() The authors 2016. Open Access under Creative Commons by Attribution Licence. Use, distribution and reproduction are unrestricted. Authors and original publication must be credited. 
changing frequencies of extreme weather and climate events. The World Economic Forum (2014) has recently placed each of these topics into a list of the top 10 risks facing the globe, in addition to a world facing 'profound political and social instability'. Therefore, it is essential for drought managers everywhere to adopt a proactive approach that identifies who or what are at risk from drought impacts, and why they have this risk. This approach has been called drought risk management, and its objective is to reduce future drought impacts by improving drought monitoring, planning, and mitigation strategies (Wilhite et al. 2005). The cycle of disaster management illustrated in Fig. 1 demonstrates how officials use crisis management to respond after events take place.

The risk management portion of the cycle, which includes monitoring and early warning, planning, and mitigation, highlights actions and activities that must occur before an event. Using drought as the event, the cycle illustrates that if officials either do nothing or only focus on crisis management, future drought risks will not be addressed and impacts will not be reduced. This key concept demonstrates why proactive drought risk management is a critical paradigm for drought officials, and will continue to be a concern under a changing climate.

This article articulates how climate information can be incorporated into the drought planning component of drought risk management. When drought managers engage in planning, the objective is to develop a plan to reduce the impacts of drought by using an effective and systematic means of assessing

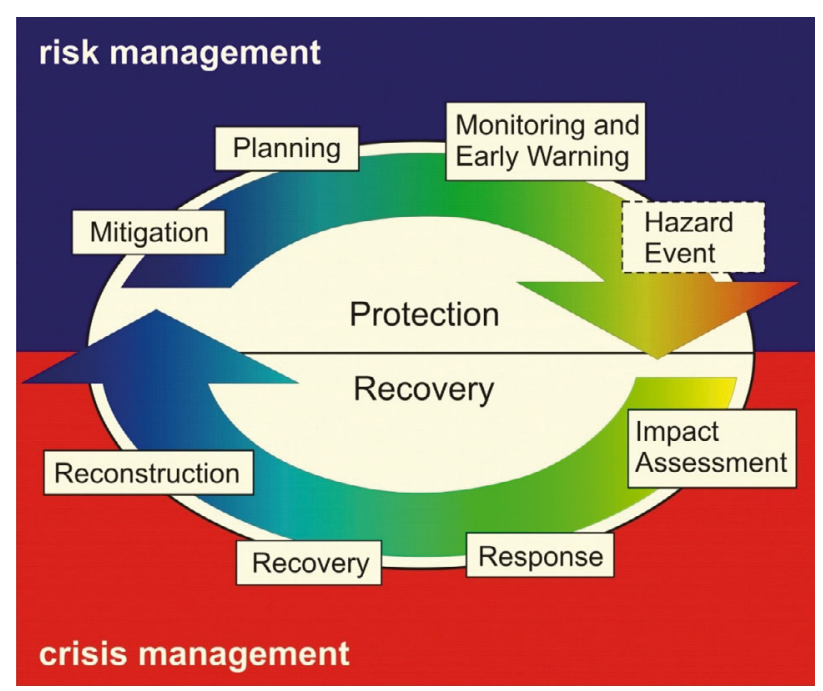

Fig. 1. The cycle of disaster management. Source: National Drought Mitigation Center drought conditions, identifying who and what is at risk from drought events, developing mitigation strategies that reduce the risk in advance of drought, and devising response options that minimize economic stress, environmental losses, and social hardships during drought. This emphasis on drought planning is applicable at any decision-making level. Drought planning helps decision-makers prepare for multiple hazards, including climate change, and will promote sustainability and natural resource management, leading toward greater economic and societal security at all levels (Geological Society of America [GSA] 2007). Climate information is central to drought planning because the connection between the assessment of current drought conditions and the activities and programs laid out within a plan is critical for the plan to be successful.

Although entities around the world have been slow to adopt a drought risk management approach (Wilhite et al. 2005), several key international initiatives are promoting the importance of drought risk management, as well as the importance of utilizing climate information and related climate services within drought risk management. In 2009, the Global Framework for Climate Services (GFCS) was established, which is a mechanism led by the United Nations to coordinate climate services worldwide. Three GFCS emphases specifically include drought: agriculture and food security, disaster risk reduction, and water. In 2013, the World Meteorological Organization (WMO) hosted the High-Level Meeting on National Drought Policy (HMNDP) in Geneva, Switzerland. Representatives from 92 nations unanimously supported a declaration encouraging countries to develop and implement national drought policies focused on drought risk management. The Integrated Drought Management Programme (IDMP), co-led by the WMO and the Global Water Partnership, was then launched to assist nations in developing a proactive national drought policy. Climate information is integral within these initiatives, and the spatial and temporal characteristics of drought spreading over multiple scales and overlapping numerous political and river basin jurisdictions mean that climate indicators and other physical indicator information are important within the drought monitoring and early warning systems (Wilhite et al. 2014). The state of Colorado in the USA provides an excellent example of how climate information can be applied within its drought-planning activities, and the state's efforts are highlighted in this article. 


\section{OVERVIEW OF PLANNING}

Planning is a task of basic problem-solving, and has been incorporated into many disciplines, including environmental issues related to land management, natural resources, water, and, more recently, drought (Bergman 2014). Water planners are used to dealing with uncertainty. The actual trajectory of population change often departs from the forecasts, the economy may grow faster or slower than anticipated, and weather extremes may develop at the least opportune moments. Water managers and users rely on data to help guide and inform their planning process. Yet, drought, a naturally occurring phenomenon, has largely been overlooked by planners as something that can be planned for, rather than simply responded to. This may be due to its relatively slow onset, or the fact that the beginning and end of a drought event can be difficult to discern, unlike other natural disasters that have very distinct beginnings and ends. This reactive approach has resulted in serious impacts and damages over the last century, some of which could have been reduced if proactive steps had been taken. While developing drought plans involves the commitment of time and money, studies show that proactive investment in natural disaster mitigation can result in significant cost savings as well as reduce overall impacts during an event (Multihazard Mitigation Council 2005).

Comprehensive drought planning provides a systematic and coordinated risk management strategy for planners to reduce overall impacts for people, animals, property, and the environment, over both the short and long term. Proactive planning also enables a more coordinated and rapid response when an event does occur - as with other natural disasters for which comprehensive planning is more common.

Comprehensive drought risk management includes the development of monitoring, mitigation, and response mechanisms that enable decision-makers to detect a drought early, respond in a timely manner, and implement measures to reduce impacts while not in active response mode. The use of climate data has historically been mainly limited to monitoring, but has broader applicability to long-term planning, especially in the face of anthropogenic climate change (Woodhouse \& Overpeck 1998). These data can provide robust metrics on which to base decisions, assess vulnerabilities, establish triggers for action, and develop mitigation strategies, all of which are critical components of overall drought risk management.

\section{OVERVIEW OF CLIMATE INFORMATION FOR DROUGHT RISK MANAGEMENT}

\subsection{Instrumental weather and climate observations}

Effective drought risk management, including comprehensive drought planning, depends on the coordinated use of multiple types of weather and climate information (Wilhite \& Buchanan-Smith 2005, Svoboda et al. 2015). Some of these data types, such as real-time drought-monitoring indicators, have seen decades of operational use in the drought-risk context, while others have been more recently or sporadically applied to drought risk management. Table 1 provides a summary of the key attributes of the different types of climate information with respect to drought planning.

The foundation of effective drought risk management is understanding the history of drought events in a locale or region (Svoboda et al. 2015). This evaluation of the physical (climatic and hydrologic) dimensions of drought has been described by Hayes et al. (2004) as the 'hazard analysis' portion of a broader drought risk analysis. The hazard analysis for drought centers on describing the frequency, intensity, duration, and spatial extent of drought occurrences (Hayes et al. 2004). This is the first step of a risk assessment. A full risk assessment would also include an analysis of vulnerability which examines the people and things that are susceptible to damage or loss as a result of a hazard.

The effective use of observed or instrumental weather and climate data is fundamental to drought risk management (Wilhite \& Buchanan-Smith 2005). Two key processes depend on instrumental data: retrospective analysis of past drought events and realtime monitoring of drought conditions. Ideally, these processes will be linked so that they use consistent data and can inform each other. Both processes are predicated on drought indicators: variables that can be used to characterize the severity, duration, and spatial extent of drought (Steinemann \& Cavalcanti 2006). Commonly used drought indicators in the USA include percent of normal precipitation, the Palmer Drought Severity Index (PDSI), the Standardized Precipitation Index (SPI), and more recently, the US Drought Monitor (Svoboda et al. 2002). The selection of the most appropriate drought indicator(s) is context-specific: it depends partly on the characteristics of a region's climate, but even more so on the particular societal and ecological vulnerabilities identified in the drought planning process, and the impacts that are desired to be reduced. Ideally, multiple drought 
Table 1. The key characteristics of the 5 types of climate information useful drought risk management

\begin{tabular}{|c|c|c|c|c|}
\hline $\begin{array}{l}\text { Instrumental weather } \\
\text { Observed climate } \\
\text { records }\end{array}$ & $\begin{array}{l}\text { d climate observations } \\
\text { Real-time monitoring }\end{array}$ & $\begin{array}{l}\text { Paleoclimate } \\
\text { records }\end{array}$ & $\begin{array}{l}\text { Seasonal climate } \\
\text { forecasts }\end{array}$ & $\begin{array}{l}\text { Climate model } \\
\text { projections }\end{array}$ \\
\hline \multicolumn{5}{|c|}{ Key information regarding drought risk } \\
\hline $\begin{array}{l}\text { Temporal and spatial } \\
\text { patterns and trends in } \\
\text { past drought events }\end{array}$ & $\begin{array}{l}\text { Current drought } \\
\text { status and direction } \\
\text { of change (improving } \\
\text { or worsening) }\end{array}$ & $\begin{array}{l}\text { Expanded perspec- } \\
\text { tive on past drought } \\
\text { events; may show } \\
\text { risk to be greater }\end{array}$ & $\begin{array}{l}\text { Anticipate onset, } \\
\text { intensification, and } \\
\text { amelioration of } \\
\text { drought }\end{array}$ & $\begin{array}{l}\text { Future anthropogenic } \\
\text { change in drought } \\
\text { risk }\end{array}$ \\
\hline \multicolumn{5}{|c|}{ Time span of information } \\
\hline $\begin{array}{l}30-300 \text { yr ago up to } \\
\text { present }\end{array}$ & Present & $\begin{array}{l}300-2000 \text { yr ago up } \\
\text { to present }\end{array}$ & $\begin{array}{l}1-12 \text { mo ahead from } \\
\text { present }\end{array}$ & $\begin{array}{l}20-80 \mathrm{yr} \text { ahead from } \\
\text { present }\end{array}$ \\
\hline \multicolumn{5}{|c|}{ Principal uses in drought risk management and planning } \\
\hline $\begin{array}{l}\text { Establish baseline } \\
\text { drought risk for a re- } \\
\text { gion; derive drought- } \\
\text { of-record; determine } \\
\text { appropriate trigger } \\
\text { levels for drought } \\
\text { response }\end{array}$ & $\begin{array}{l}\text { When triggers } \\
\text { for indicators are } \\
\text { reached, implement } \\
\text { responses }\end{array}$ & $\begin{array}{l}\text { Assess adequacy of } \\
\text { observed record in } \\
\text { describing baseline } \\
\text { drought risk; derive } \\
\text { more stressful } \\
\text { droughts-of-record }\end{array}$ & $\begin{array}{l}\text { Use in combination } \\
\text { with triggers to } \\
\text { prepare and respond } \\
\text { to emerging drought }\end{array}$ & $\begin{array}{l}\text { Anticipate future } \\
\text { changes in drought } \\
\text { risk and prepare with } \\
\text { long-term policy and } \\
\text { investment }\end{array}$ \\
\hline \multicolumn{5}{|l|}{ Limitations } \\
\hline $\begin{array}{l}\text { Do not capture the } \\
\text { full range of natural } \\
\text { climate variability; } \\
\text { may underestimate } \\
\text { future drought risk }\end{array}$ & $\begin{array}{l}\text { Indicators may not } \\
\text { consistently capture } \\
\text { impacts }\end{array}$ & $\begin{array}{l}\text { Uncertainty in the } \\
\text { proxy information; } \\
\text { limited to annual } \\
\text { resolution; not } \\
\text { available for many } \\
\text { locations }\end{array}$ & $\begin{array}{l}\text { Difficult to translate } \\
\text { the probabilistic } \\
\text { forecasts into } \\
\text { threshold-based } \\
\text { responses }\end{array}$ & $\begin{array}{l}\text { Large uncertainties } \\
\text { in future changes, } \\
\text { which require consi- } \\
\text { deration of multiple } \\
\text { projections; complex } \\
\text { datasets that are diffi- } \\
\text { cult to obtain, analy- } \\
\text { ze and interpret }\end{array}$ \\
\hline
\end{tabular}

indicators will be used in the hazard analysis (e.g. SPI and PDSI), since the unique indicators will represent different dimensions of the same drought event.

The most basic hazard analysis will involve plotting time-series of these indicators, over their full available records, for 1 or more points within the region of interest. From there, the hazard analysis can include these additional components:

- Estimating return periods of droughts of different intensity, duration, and spatial extent

- Looking for consistent patterns in the temporal and spatial features of drought (seasonality of emergence, characteristic spatial footprint)

- Evaluating long-term trends in drought occurrence

- Identifying modes of climate variability (e.g. ENSO phase) associated with greater or lesser drought risk

- Identifying a 'drought of record' that represents a worst-case scenario during the period of instrumental record

This analysis can then be used to determine the baseline drought risk to inform overall drought planning.
The climate data used in a hazard analysis do not necessarily speak for themselves. To inform overall drought risk analysis, the climatic indicators need to be related to the actual drought impacts experienced during the period of instrumental record (National Drought Mitigation Center [NDMC] 2011). When particular historic drought impacts were experienced, such as reservoir depletion, crop losses, or wildfire outbreaks, what were the values of the different indicators? Those values at which the likelihood of certain impacts becomes much greater can then be used as drought triggers in drought plans; i.e. determinants of when a drought response begins or ends (Steinemann 2003).

Through this process of calibration between the data (indicators) and the impacts, the hazard analysis also serves as a testing ground for effective real-time drought monitoring.

Drought indicators can be a single data information source, like the SPI, reservoir storage levels, or soil moisture, or they can be multiple information sources that are compiled into a composite, like the US Drought Monitor (NDMC 2015a). The indicators that, 
retrospectively, have been effective in capturing key drought impacts are likely to serve well in the future. Real-time monitoring is best founded on indicators for which there is a long history (50 yr or longer), so that the current conditions can be placed into the context of not only the history of that indicator, but the history of drought impacts. Even the US Drought Monitor, which has been produced as a US nationwide product only since 1999, is based on underlying indicators, some of which have approximately $100 \mathrm{yr}$ records in the USA.

Continual monitoring of select indicators, even during non-drought periods, provides baseline data and can help detect emerging drought conditions long before impacts are felt (Wilhite \& BuchananSmith 2005). Using indicators to determine thresholds or triggers at which actions should be taken provides guidance to decision-makers during the onset of an event (Steinemann et al. 2005). These should be viewed as guidelines rather than rules as droughts seldom look the same from one event to the next: some are prolonged and persistent but not initially intense, while others are short-lived and extremely severe. A response that made sense during one event may not be applicable during the next. The next 3 types of climate information - paleoclimate records, seasonal climate forecasts, and climate projections have truly emerged as usable data only in the past 10 to $20 \mathrm{yr}$, and none have been widely incorporated into drought risk management and drought planning. Each addresses a different shortcoming of the instrumental record, and used in conjunction with the other types, each can add significant value to the planning process, reducing vulnerability to unanticipated drought conditions.

\subsection{Paleoclimate records}

Instrumental climate records are extraordinarily rich in terms of the spatial density and the number of variables measured, but very limited in temporal extent. Only in a handful of locations worldwide do robust instrumental records extend back $>200 \mathrm{yr}$, and most regions have data extending back $<100 \mathrm{yr}$ (Bradley 1991, NRC 1998). We know that this window onto the past is too short to capture the full range of natural climate variability experienced during the late Holocene - variability that could plausibly recur in the future (NRC 1998, Hoerling et al. 2013).

Paleoclimate records use environmental proxies, such as stable isotopes from ice-cores and corals, pollen from lake sediment cores, and the width and density of tree rings, to reconstruct past climate prior to the instrumental period. Hydroclimatic reconstructions that capture paleodrought occurrence constitute the largest category of paleoclimate reconstructions available from the World Data Center for Paleoclimatology hosted by the US National Oceanic and Atmospheric Administration National Centers for Environmental Information (NOAA 2016). Reconstructions of precipitation, streamflow, and/or PDSI, mainly from tree rings, are available for locations on all continents except Antarctica, with the greatest availability for the USA, northern Mexico, southern Canada, western Europe, and central and southeastern Asia. These paleodrought reconstructions are typically from 300 to 2000 yr long.

The longer window onto the past afforded by paleodrought reconstructions almost always shows drought events that are more intense, are of greater duration, and/or have a larger spatial extent than any seen during the instrumental period (Meko \& Woodhouse 2011). For example, tree-ring reconstructions of Colorado River annual streamflow in the southwestern USA show a 'megadrought' during the mid1100s in which persistently dry conditions lasted for almost $60 \mathrm{yr}$, over twice as long as any comparably dry period observed since 1900 (Meko et al. 2007). Moreover, paleodrought records tend to show that drought risk fluctuates on century time scales: in the western USA, the 20th century was generally less drought-prone than the preceding 4 to 20 centuries (Hoerling et al. 2013). From a drought-planning perspective, paleodrought records enlarge the view of what events are possible and should be prepared for, and reduce the likelihood of surprise by future events that are 'unprecedented' relative to the instrumental record. Paleodrought records can also be used to estimate historic return intervals for events that are too rare to be assessed by the instrumental period alone (Biondi et al. 2008). While paleodrought reconstructions are not available in all locations, where they are available, they provide valuable insight and are worth examining to see how they compare with the instrumental record of drought.

\subsection{Seasonal climate forecasts}

Instrumental climate records, supplemented by paleoclimate records, provide a good sense of the mean or climatological drought risk. A hazard analysis (as described in the above section) may also identify time-varying components of drought risk, such as changes associated with ENSO state. But, even if 
present in the instrumental record, it is not straightforward for drought planners to use these features in a predictive mode. Seasonal climate forecasts offer a more robust way to explicitly incorporate the evolving variation in drought risk into drought planning and response, anticipating changes before they occur.

In the past few decades, advances in our understanding of modeling, ENSO, and other persistent climate features have led to skillful operational climate forecasts on seasonal time scales (1 to $12 \mathrm{mo}$ ) for precipitation and temperature (Livezey \& Timofeyeva 2008). The skill of these forecasts varies by region and season, with the highest skill tending to be in areas that have strong ENSO signals (Barnston et al. 2010). Seasonal climate forecasts for precipitation and temperature for 3 mo periods are now available on a near-global basis through the International Research Institute for Climate and Society, and through the meteorological agencies of 12 countries, including the USA, Canada, Russia, France, Japan, and South Africa, who contribute to the World Meteorological Office's program for long-lead forecasts.

The potential value of seasonal forecasts to drought risk management is clear: anticipating the emergence, intensification, or amelioration of drought events up to several months in advance. But adoption of seasonal climate forecasts has been slow for many applications, including drought risk management (Marshall et al. 2011). Several factors have been found to constrain the use of seasonal climate forecasts, including difficulty interpreting their probabilistic nature, insufficient perceived reliability, and mismatch with the spatial and temporal scales of decision-making (Callahan et al. 1999, Hartmann et al. 2002, Rayner et al. 2005, Lowrey et al. 2009, Bolson et al. 2013). These challenges notwithstanding, Steinemann (2006) laid out a practical method for using seasonal climate forecasts in short-term drought planning and preparedness, and demonstrated the added value of the forecasts.

\subsection{Climate model projections}

While instrumental records of climate are necessary for drought planning, even when supplemented by paleodrought records they may not be sufficient to fully describe all future drought risk. Anthropogenic climate change poses a considerable challenge for drought risk management. Future drought risk will reflect both natural climate variability, which is represented in instrumental and paleo records, and anthropogenically forced climate changes, which are not (Solomon et al. 2011, Deser et al. 2012). Use of climate model projections can provide insight into how drought risk may change as a result of these forced changes.

Future projections from global climate models are an attempt at numerically representing the fundamental physics of the climate system, and reflect our best knowledge of climate processes and anthropogenic climate forcings such as greenhouse gas emissions (Barsugli et al. 2009). These projections indicate that systematic shifts in drought risk will likely occur in most parts of the world over the coming decades as the effects of anthropogenic climate change are more deeply felt (Dai 2013). There is very high confidence in the projected warming of average temperatures in all regions, which will tend to increase evapotranspiration from the land surface and worsen drought conditions for a given precipitation deficit (Zhao \& Dai 2015). The projections of precipitation change are generally less certain, though there is a strong model consensus of decreased future precipitation in many areas from $10^{\circ}$ to $35^{\circ} \mathrm{N}$ and $\mathrm{S}$, including the southwestern USA, the southern Mediterranean region, and western Australia. These areas are projected to experience the greatest shift towards increasing future drought risk (Sheffield \& Wood 2008, Dai 2013).

While the broad implications of climate projections for drought risk management are clear, as with seasonal climate forecasts, incorporating this information into planning is not straightforward (Barsugli et al. 2009). For a given location and time period, there is a large range in projected future changes in climate, reflecting both unknowable future changes in the societal factors that govern greenhouse gas emissions and uncertainty regarding the physical response of the climate system to additional emissions (Mote et al. 2011). To capture the former uncertainty, several different emissions trajectories are used to drive the models, while the latter uncertainty is reflected in the spread among the several dozen climate models under a given emissions trajectory. Thus, for any planning exercise, it is important to consider multiple projections that collectively represent both types of uncertainties (Mote et al. 2011).

Climate projections need to be approached with a fundamentally different mindset to other types of climate information. The broader set of climate projections is best used to facilitate exploration of physically plausible climate futures, rather than attempting to derive a precise quantification of future risk. Scenario planning (Means et al. 2010) is one mechanism to do this, as discussed in Section 4. 


\subsection{Making climate information more usable for drought planning}

Despite all of the types of climate data now available, and their potential utility, there are persistent barriers to integrating this information into management and planning, including lack of awareness of the data, inability to access the desired data, inadequate interpretation of the data, mismatch of temporal and/or spatial qualities of the data with the intended application, and perceived lack of utility of the data (Rayner et al. 2005, Lemos et al. 2012, Bolson et al. 2013).

To successfully bridge this 'usability gap,' it has been found that decision-makers and researchers need to work collaboratively and iteratively to develop information and tools that are directly applicable to the planning process (Lemos \& Morehouse 2005, Dilling \& Lemos 2011). In this model of 'co-production' of climate information and services, users can clearly voice what their needs are and researchers can develop tools specifically targeted to meet those needs. It also allows researchers greater opportunities to interact with drought and water professionals to ensure they understand the inherent uncertainties and are using the data in an appropriate and reliable manner (Bolson et al. 2013).

The acknowledged value of co-production is reflected in the rapidly increasing number of entities that serve as 'boundary organizations' (Dilling \& Lemos 2011), co-producing usable climate information through both the development of new products and tools and the translation and customization of existing data. In the USA, the NOAA Regional Integrated Sciences \& Assessments (RISA) program was an early pioneer of this model in the mid-1990s, along with the NDMC, Regional Climate Centers, and many state climatologists' offices. More recently, the Water Utility Climate Alliance, the US Department of Interior Climate Science Centers, the US Department of Agriculture Regional Climate Hubs, and others have brought together climate scientists with decision-makers in many sectors to identify and assess risks from climate, including drought. In Europe, the Seasonal-to-decadal climate Prediction for the improvement of European Climate Services (SPECS), European Provision of Regional Impacts Assessments on Seasonal and Decadal Timescales (EUPORIAS), and Climate Science Research Partnership (UK) are following a co-production model to improve the usefulness of climate science (Buontempo et al. 2014).

The experiences of these boundary organizations indicate that to broaden the use of climate informa- tion, e.g. in drought planning, and overcome the barriers listed above, there is no real substitute for repeated engagement between the community of technical experts and those who use the information (Ferguson et al. 2014). 'Early adopters' of new information, such as in the Colorado case study presented below, can also help convey the feasibility and benefits of using new information to their peers, and point to potential data sources and analytical approaches.

\section{THE DROUGHT-PLANNING PROCESS: WHERE CLIMATE INFORMATION FITS IN}

The purpose of drought planning depends on the ultimate societal objectives. In an agricultural region, this may be protection and preservation of irrigation water during the growing season, while in a more urban area, it is likely more focused on water for essential indoor use by its residents. Regardless of the objectives, effective use of the aforementioned climate data can enhance and improve overall drought preparedness.

The state of Colorado, in the southwestern USA, has taken a comprehensive approach to drought risk management and drought planning by identifying an effective and systematic means of assessing drought conditions, identifying who and what is at risk from drought events, developing mitigation strategies that reduce the risk of drought in advance, and devising response options that minimize economic stress, environmental losses, and social hardships during drought. The planning process (Colorado Water Conservation Board 2010) for drought can be broken down into 8 distinct steps (Fig. 2), 6 of which can, and should, use some level of climate information.

Step 1 lays out the plan's objectives which will differ from place to place, dependent upon the community's values and needs. This step is largely independent of climate data.

Step 2 relies upon the observed climate and paleoclimate records to examine and understand when and where drought has affected resources in the past. By examining where impacts have occurred during previous events, it is possible to not only gather information to inform a risk assessment, but also to gauge the effectiveness of adaptive risk management strategies that have been implemented previously.

Steps 3 and 4 should be informed by the information in Step 2, as existing and future vulnerabilities are identified. This is also an ideal place to incorporate climate change projections to examine how vulnerabilities may shift under a warming climate. For 


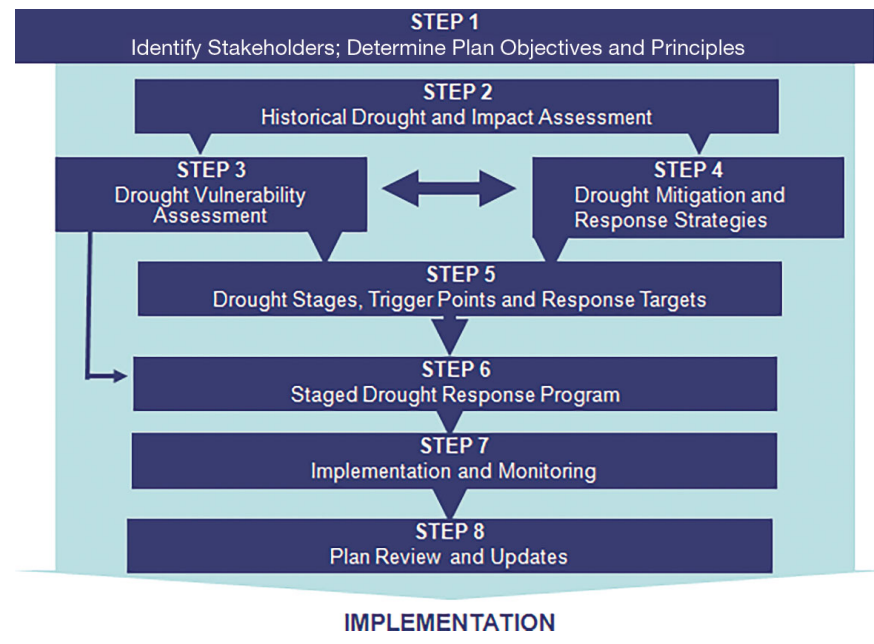

Fig. 2. Steps in the development of a drought management plan (see Section 4 for further information on the steps). Adapted from Colorado Water Conservation Board (2010)

instance, in Colorado, a recent analysis showed that under hotter and drier conditions, heavily appropriated river basins would not only be unable to meet additional future water demands, but would also be unable to meet existing needs, thereby introducing new vulnerabilities. This information will enable state and local planners, as well as water managers, to start preparing for and addressing those shortages long before the impacts are ever felt (Colorado Water Conservation Board 2015). Paleodrought information can also be used in this step to help broaden the realm of plausible future conditions based on what occurred prior to the observed record.

Based on the vulnerability assessment findings, actions and concrete mitigation strategies can be developed and implemented that will decrease the extent or severity of future impacts. For instance, if, during previous drought events, there have been severe drought impacts in a particular region with limited reservoir storage, one may be able to determine that additional storage or a revised operation of existing structures will decrease overall impacts. Similarly, if a region has proven resilient to drought events, one can examine what adaptive risk management practices are in place that may be applicable to other regions.

Step 5 addresses one of the most problematic pieces of dealing with drought response only during the onset of an event. When in crisis or response mode, actions and decisions can often become politicized and contentious, which in turn slows down response and decision-making. Identifying appropriate climate indicators to monitor drought, and agree- ing upon climatic 'trigger points' (thresholds) for response prior to the onset of drought can expedite the response process and help to speed aid to those most in need.

Step 6 develops a staged drought response plan, based on the pre-determined thresholds identified in Step 5, and allows for policy makers to respond in a manner that best suits the severity, duration, and intensity of an ongoing drought event. This also incorporates activation at an early stage that slowly ramps up as an event intensifies; resulting in less shock to water users. Observed climate data can help inform policy makers about the historical context of an event, and how a current event may be similar or different. This information, along with impacts and vulnerabilities, can inform overall response strategies, and help to lessen impacts though more rapid and proactive actions.

Step 7 incorporates consistent and continual monitoring, which is critical for effective drought risk management. The use of climate data to detect the drought condition as early as possible speeds the response process, and when coupled with appropriate actions, can reduce the overall impacts. This step is also important in lengthening the record of observed data so that trends can be detected as the long-term climate shifts.

Step 8 ensures that the plan is a living document that reflects current priorities and values through regular updates and review.

\subsection{Colorado: a case study of the broader use of climate information in drought and climate planning}

Colorado has a long history of robust monitoring that relies upon snowpack data, forecasted and actual stream flow, SPI, PDSI, the US Drought Monitor, and experimental long-term forecasts that incorporate the potential effects of ENSO on Colorado's weather. These are reported monthly at a Water Availability Task Force meeting and summarized in a drought update that is distributed to decision-makers and stakeholders. This provides an opportunity for municipal water providers, agricultural users, government agencies, and stakeholders to collaborate on monitoring of and response to emerging conditions. These are many of the same entities actively involved in mitigation efforts.

In addition, Colorado examines vulnerabilities sector by sector at the county level in both a quantitative and qualitative manner. The vulnerability 
assessment directly informs decisions on mitigation strategies as it provides a means to rank or prioritize mitigation actions to provide the most relief for the least cost. In some sectors, climate data is a quantitative input to this assessment. For instance, the southeastern plains of the state are dominated by dryland farmers dependent upon natural precipitation for crop growth, rather than irrigation, yet historically this region has lacked a comprehensive network of monitoring stations. A 2010 analysis showed that this region of the state was among the most vulnerable to agricultural impacts as a result of drought. In 2011 alone, more than $\$ 110$ million in lost economic activity occurred as a result of drought (Gunter et al. 2012). Since that time, the state has expended resources to increase monitoring in the region to ensure earlier detection of future droughts. The state has also upgraded monitoring stations to report data hourly, making the data more useful for agricultural producers in informing their management decisions. Increasing the user base also helps to build support for the network and justify expenditures for maintenance.

To plan for the longer term, Colorado has examined the potential impacts of climate change, including more frequent, intense, and severe droughts, using analyses of both the paleodrought record and future climate projections. This has provided insight on what droughts might look like in the future and how these events might compare to those in both the paleodrought and observed record (Colorado Water Conservation Board 2013).

Developing planning strategies takes time, and understanding the range of what may be plausible helps to ensure that planning approaches are both comprehensive and nimble enough to address a wide range of possibilities. To do this, Colorado uses a scenario planning approach in which climate is just 1 of 9 primary drivers that inform 5 future scenarios, as outlined in Table 2 (Colorado Water Conservation Board 2015). Both observed climate data and future climate projections are used to define the climate component of the scenarios. This provides policy makers with a range of potential future conditions and, through using the climate scenarios as inputs to hydrology models, their corresponding impacts on water supplies. It also illustrates how climate change, in conjunction with other uncertainties, such as population growth, land-use patterns, regulation, and energy development, can compound water supply concerns. Preparing for a broad range of possible future conditions helps to build flexibility into the planning process and ensure that the state is better prepared to address whatever future unfolds (Colorado Water Conservation Board 2015).

The incorporation of information from both paleodrought records and future climate projections in the 2013 state drought plan revision and subsequent state planning documents was built on a decade of engagement with local climate scientists, hydrologists, and consulting engineers. This included convening a technical advisory group of about 20 experts to review the proposed methodologies for climate analyses, and the state's participation in multiple climate vulnerability assessments. These activities helped build technical capacity within the state agencies to more effectively use climate information, and gave the researchers exposure to the context of planning and decision-making.

The state has also incorporated quantitative 'trigger points' that guide the activation of the staged drought response plan. These trigger points were developed by analyzing observed climate data and overlaying that information with past impacts. This provided quantitative thresholds at which certain impacts are likely to start occurring. The existence of these pre-determined decision points has helped to depoliticize the activation process and speed aid to those most impacted by drought. Without the use of long-term observed climate records, it would not have been possible to accurately develop these thresholds.

These trigger points were developed after the 2002 drought, which was the driest year in Colorado on record. In 2012, the state faced another severe statewide drought in what turned out to be the second-driest year on record, but by using the triggers, the state began responding to the drought before the impacts became as severe as in 2002. As a result of this and other changes made after the 2002 drought, the overall drought response in Colorado was more coordinated in 2012 than in 2002 (Ryan \& Doesken 2013), with entities such as municipal water providers implementing response measures sooner than previously implemented, and tourism and recreation outfitters diversifying activities to offset revenue losses.

Lastly, the state details 78 specific prioritized mitigation actions that support the 8 overall goals of the drought mitigation and response plan. These have been systematically identified to reduce overall impacts of future drought events. These are updated regularly and are heavily informed by the vulnerability and impact assessments. Lead agencies are identified as potential funding sources and collaborative partners, ensuring each agency knows its responsibilities. Increased and enhanced collection of climate 


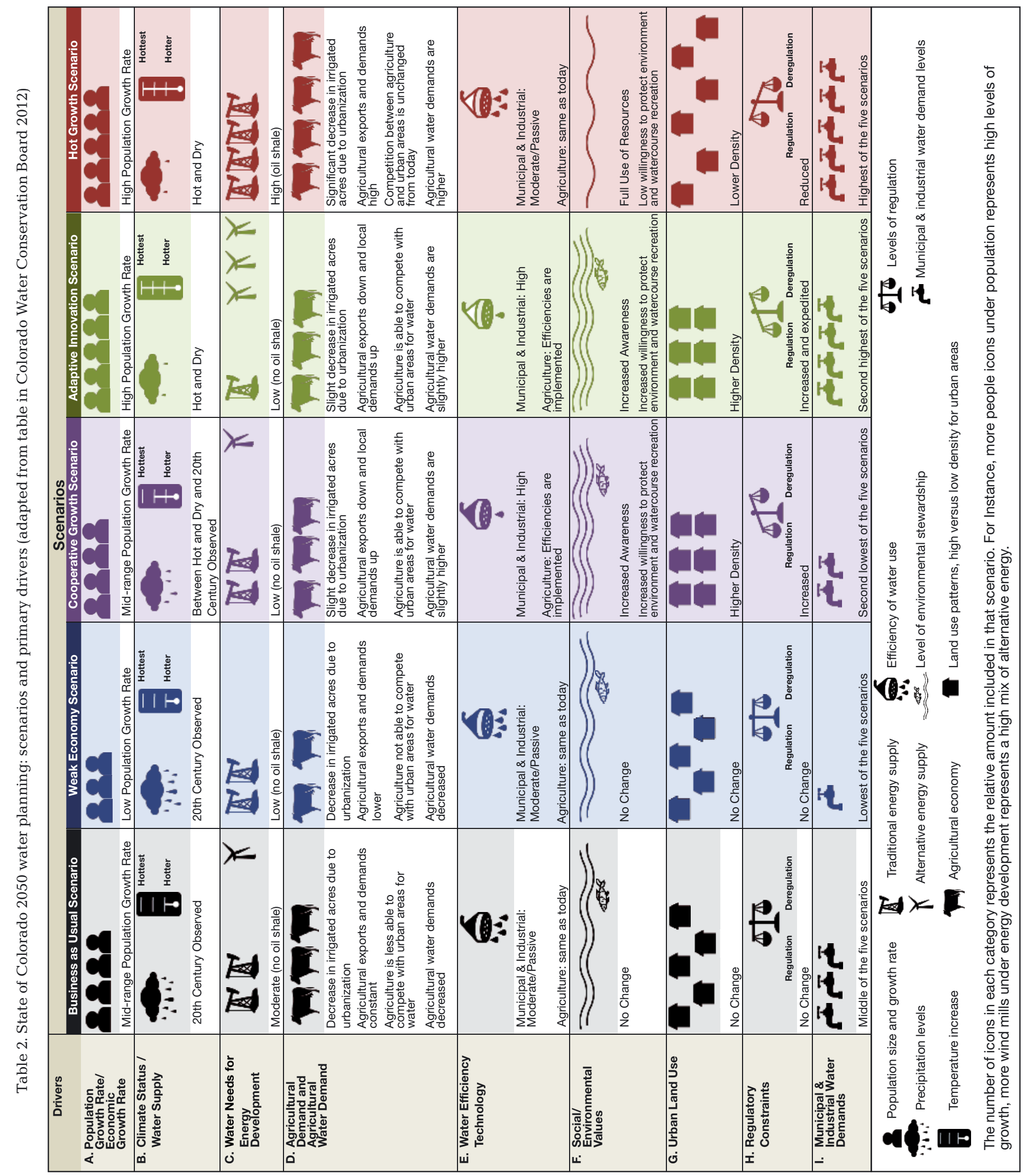


data is included in these mitigation actions, and as a result, the state has been able to dedicate funds to improve both.

\subsection{Interconnections with other planning processes}

Drought planning is most effective when it does not exist in its own silo, but rather is integrated with other long- and short-term planning efforts. Water resource plans, emergency management plans, and land-use plans are a few examples of efforts that could all be further integrated into drought planning efforts. Integrated planning is not new. Land-use plans rely on floodplain mapping, emergency management plans examine where fault lines are, water resource planning uses demographics to ensure adequate water supply. Yet, drought has not traditionally been included in this integration (Bergman 2014). Consequently, many communities lack these plans altogether, or if they exist, they are not updated as frequently as they should be. Because long intervals may be present between drought events, an outdated plan will not reflect changes in the values of a community. Integrating planning efforts will help to ensure that they are frequently updated and remain relevant.

The use of scenario planning is one way to integrate multiple planning elements into a single streamlined process. Unlike planning efforts that rely upon a predefined static future point, scenario planning recognizes that the future will be shaped by a number of diverse drivers, all of which are equally important and all of which have inherent uncertainties associated with them. The development of a scenario could use just a few drivers or it could incorporate a large number. By widening the spread of possible future conditions one prepares for, the likelihood that planning efforts are ample and appropriate for the conditions that actually unfold is increased (Colorado Water Conservation Board 2015).

\subsection{Beyond Colorado}

The Colorado case study indicates the value of incorporating multiple types of climate information into the drought planning process. In the USA, other similar case studies can be found at various scales, including for individual livestock producers (NDMC 2015b) and municipalities (Denver Water 2015). The NDMC recently developed a tool called the Drought
Risk Atlas (http://droughtatlas.unl.edu/) designed to assist planners to better incorporate climate information into their drought planning processes at different scales. At the international level, one recent example is an effort taking place in northeast Brazil and supported by the World Bank. This effort has led to the creation of a monthly drought monitoring assessment tool and process called the Monitor de Secas do Nordeste (the Northeast Drought Monitor, or MSNE) adapted from the US Drought Monitor tool process (http://monitordesecas.ana.gov.br/). In addition to monitoring drought conditions in the 9 states across the region, drought planning at several scales within the region is simultaneously taking place with the specific intent that the drought early warning provided by the MSNE will be linked within the preparedness plans being developed (Hayes et al. 2016). These recent efforts in Brazil have relied heavily upon the lessons learned from experiences within the USA, Mexico, and Spain (Hayes et al. 2016).

\section{CONCLUSIONS}

While climate and weather data have long been used for drought monitoring, their use in long-term drought risk management through comprehensive long-term planning has been more recent and limited. When drought managers engage in comprehensive planning, impacts can be lessened or avoided through developing mitigation strategies that reduce the risk of drought in advance, and devising response options that minimize economic stress, environmental losses, and social hardships during drought. This straightforward planning process is applicable at any decision-making level. Additional information and research on avoided costs as a result of comprehensive planning is limited and would greatly benefit the drought planning process as well as communities' abilities to prioritize efforts.

Comprehensive drought planning helps decisionmakers prepare for multiple hazards, including climate change. Broader adoption and integration of climate data in long-term drought planning and preparedness could help to increase sustainability of natural resources and could help to increase economic and societal resiliency.

\section{LITERATURE CITED}

Barnston AG, Li S, Mason SJ, DeWitt DG, Goddard L, Gong X (2010) Verification of the first 11 years of IRI's seasonal climate forecasts. J Appl Meteorol Climatol 49:493-520 
Barsugli JJ, Anderson C, Smith JB, Vogel JM (2009) Options for improving climate modeling to assist water utility planning for climate change. Final Report, Water Utility Climate Alliance, San Francisco. www.wucaonline.org/ assets/pdf/actions_whitepaper_120909.pdf

Bergman C (2014) Improving drought management for transboundary river basins in the United States through collaborative environmental planning. PhD dissertation, University of Nebraska-Lincoln

Biondi F, Kozubowski TJ, Panorska AK, Saito L (2008) A new stochastic model of episode peak and duration for ecohydro-climatic applications. Ecol Modell 211:383-395

Bolson JB, Martinez CJ, Srivastava P, Breuer N, Knox P (2013) Climate information use among southeast US water managers: beyond barriers and toward opportunities. Reg Environ Change 13:141-151

Bradley RS (1991) Pre-instrumental climate: how has climate varied during the past 500 years. In: Schlesinger ME (ed) Greenhouse gas-induced climatic change: a critical appraisal of simulations and observations. Elsevier, Amsterdam, p 391-410

Buontempo C, Hewitt CD, Doblas-Reyes FJ, Dessai S (2014) Climate service development, delivery and use in Europe at monthly to inter-annual timescales. Clim Risk Manage 6:1-5

Callahan B, Miles E, Fluharty D (1999) Policy implications of climate forecasts for water resources management in the Pacific Northwest. Policy Sci 32:269-293

Colorado Water Conservation Board (2010) Municipal drought management plan guidance document. Denver, CO. http: //cwcb.state.co.us/technical-resources/drought-planningtoolbox/Documents/DroughtPlanningResources/Municipa IDroughtMgmtPlanGuidanceDocFull.pdf

Colorado Water Conservation Board (2012) Draft scenarios. Colarado's water supply future. Interbasin Compact Committee Annual Report, Denver, CO. p 7-8. http://www2. cde.state.co.us/artemis/nrserials/nr1251internet/nr1251 2012internet.pdf

Colorado Water Conservation Board (2013) Colorado drought mitigation and response plan. Denver, CO. http: //cwcbweblink.state.co.us/WebLink/0/doc/173111/ Electronic.aspx?searchid=45a1d11c-9ccf-474b-bed42 bccb2988870

Colorado Water Conservation Board (2015) Colorado's water plan. Denver, CO. http://coloradowaterplan.com/

$>$ Dai A (2013) Increasing drought under global warming in observations and models. Nat Clim Change 3:52-58

Denver Water (2016) Planning for an uncertain future. www. denverwater.org/SupplyPlanning/DroughtInformation/ UncertainFuture/ (site regularly updated; data accessed 2015)

> Deser C, Phillips A, Bourdette V, Teng H (2012) Uncertainty in climate change projections: the role of internal variability. Clim Dyn 38:527-546

Dilling L, Lemos MC (2011) Creating usable science: opportunities and constraints for climate knowledge use and their implications for science policy. Glob Environ Change 21:680-689

Ferguson DB, Rice J, Woodhouse C (2014) Linking environmental research and practice: lessons from the integration of climate science and water management in the western United States. Climate Assessment for the Southwest, University of Arizona, Tucson, AZ. www.climas. arizona.edu/publication/report/linking-environmentalresearch-and-practice
Geological Society of America (GSA) (2007) Managing drought: a roadmap for change in the United States. Conf Rep 'Managing drought and water scarcity in vulnerable environments', 18-20 Sept, 2006. The Geological Society of America, Longmont, CO. www.geosociety.org/ meetings/06drought/roadmapHi.pdf

Gleick P (2014) Water, drought, climate change, and conflict in Syria. Weather Clim Soc 6:331-340

Gunter A, Goemans C, Pritchett J, Thilmany D (2012) The economic impact of the 2011 drought on southern Colorado: a combined input-output and EDMP analysis. Colorado Water Conservation Board Project Report http:// cwcbweblink.state.co.us/WebLink/0/doc/168084/ Electronic.aspx? searchid=f52adb2f-1a9c-4bca-91aa$5 \mathrm{~b} 5 \mathrm{ec} 2 \mathrm{c} 368 \mathrm{~cd}$

Hartmann HC, Pagano TC, Sorooshian S, Bales R (2002) Confidence builders: evaluating seasonal climate forecasts from user perspectives. Bull Am Meteorol Soc 83: 683-698

> Hayes MJ, Wilhelmi O, Knutson C (2004) Reducing drought risk: bridging theory and practice. Nat Hazards Rev 5: 106-113

Hayes M, Pérez ML, Andreu J, Svoboda M, Fuchs B, Cortés FA, Engle N (2016) Perspectives from the outside: contributions to the drought paradigm shift in Brazil from Spain, Mexico, and the United States. In: De Nys E, Engle N, Magalhães AR (eds) Drought in Brazil: proactive management and policy. CRC Press, Boca Raton, FL, p 81-90

Hoerling MP, Dettinger M, Wolter $\mathrm{K}$, Lukas J and others (2013) Present weather and climate: evolving conditions. In: Garfin G, Jardine A, Merideth R, Black M, LeRoy S (eds) Assessment of climate change in the southwest United States: a report prepared for the National Climate Assessment. Southwest Climate Alliance, Island Press, Washington, DC, p 74-100

Howitt RE, Medellín-Azuara J, MacEwan D, Lund JR, Sumner DA (2014) Economic analysis of the 2014 drought for California agriculture. Center for Watershed Sciences, University of California, Davis. http://watershed.ucdavis. edu/files/biblio/DroughtReport_23July2014_0.pdf

Howitt RE, MacEwan D, Medellín-Azuara J, Lund JR, Sumner DA (2015) Economic analysis of the 2015 drought for California agriculture. Center for Watershed Sciences, University of California, Davis, CA. http://watershed. ucdavis.edu/files/biblio/Final_Drought\%20Report_ 08182015_Full_Report_WithAppendices.pdf

> Lemos MC, Morehouse BJ (2005) The co-production of science and policy in integrated climate assessments. Glob Environ Change 15:57-68

> Lemos MC, Kirchhoff CJ, Ramprasad V (2012) Narrowing the climate information usability gap. Nat Clim Change 2:789-794

Livezey RE, Timofeyeva MM (2008) The first decade of longlead US seasonal forecasts: insights from a skill analysis. Bull Am Meteorol Soc 89:843-854

Lowrey J, Ray A, Webb R (2009) Factors influencing the use of climate information by Colorado municipal water managers. Clim Res 40:103-119

> Marshall NA, Gordon IJ, Ash AJ (2011) The reluctance of resource-users to adopt seasonal climate forecasts to enhance resilience to climate variability on the rangelands. Clim Change 107:511-529

Means EG III, Laugier MC, Daw JA, Kaatz L, Waage M (2010) Decision support planning methods: incorporating 
climate change uncertainties into water planning. Final report January 2010. Water Utility Climate Alliance, San Francisco. http://www.wucaonline.org/assets/pdf/ actions_whitepaper_012110.pdf

Meko DM, Woodhouse CA (2011) Dendroclimatology, dendrohydrology, and water resources management. In: Hughes MK, Swetnam TW, Diaz HF (eds) Tree rings and climate: progress and prospects. Springer, New York, NY, p 231-261

Meko DM, Woodhouse CA, Baisan CA, Knight T, Lukas J, Hughes MK, Salzer MW (2007) Medieval drought in the Upper Colorado River Basin. Geophys Res Lett 34: L10705, doi:10.1029/2007GL029988

Mote P, Brekke L, Duffy PB, Maurer E (2011) Guidelines for constructing climate scenarios. Eos Trans AGU 92: 257-258

Multihazard Mitigation Council (2005) Natural hazard mitigation saves: an independent study to assess the future savings from mitigation activities. Vol 1, Findings, conclusions and recommendations. National Institute of Building Sciences, Washington, DC. http://c.ymcdn.com/sites/www. nibs.org/resource/resmgr/MMC/hms_vol1.pdf

National Drought Mitigation Center (NDMC) (2011) Drought-ready communities: a guide to community drought preparedness. http://drought.unl.edu/portals/0/ docs/DRC_Guide.pdf

NDMC (2015a) US drought monitor classification scheme. http://droughtmonitor.unl.edu/AboutUs/ClassificationScheme.aspx

NDMC (2015b) Sample drought plan—south central Kansas. http://drought.unl.edu/ranchplan/WriteaPlan/SampleDroughtPlans/SouthCentralKansasAlexanderRanch.aspx

NOAA (National Oceanic and Atmospheric Administration) (2016) Climate reconstructions. World Data Center for Paleoclimatology. www.ncdc.noaa.gov/data-access/ paleoclimatology-data/datasets/climate-reconstruction (accessed 22 April 2016)

NRC (National Research Council) (1998) Decade-to-century-scale climate variability and change: a science strategy. Panel on Climate Variability on Decade-to-Century Time Scales, Board on Atmospheric Sciences and Climate, Commission on Geosciences, Environment, and Resources, National Research Council. National Academy Press, Washington, DC, doi:10.17226/6129

Rayner S, Lach D, Ingram H (2005) Weather forecasts are for wimps: why water resource managers do not use climate forecasts. Clim Change 69:197-227

Ryan W, Doesken N (2013) Drought of 2012 in Colorado. Climatology Report 13-01. Dept. of Atmos. Sci., Colorado State University. http://ccc.atmos.colostate.edu/pdfs/

Editorial responsibility: Donald Wilhite (Guest Editor), Lincoln, Nebraska, USA climo_rpt_13_1.pdf

Sheffield J, Wood EF (2008) Projected changes in drought occurrence under future global warming from multimodel, multi-scenario, IPCC AR4 simulations. Clim Dyn 31:79-105

Solomon A, Goddard L, Kumar A, Carton J and others (2011) Distinguishing the roles of natural and anthropogenically forced decadal climate variability: implications for prediction. Bull Am Meteorol Soc 92:141-156

Steinemann A (2003) Drought indicators and triggers: a stochastic approach to evaluation. J Am Water Resour Assoc 39:1217-1234

Steinemann A (2006) Using climate forecasts for drought water management. J Appl Meteorol Climatol 45: 1353-1361

Steinemann A, Cavalcanti L (2006) Developing multiple indicators and triggers for drought plans. J Water Resour Plan Manage 132:164-174

Steinemann A, Hayes M, Cavalcanti L (2005) Drought indicators and triggers. In: Wilhite D (ed) Drought and water crises: science, technology, and management issues. CRC Press, Boca Raton, FL, p 71-92

Svoboda M, LeComte D, Hayes M, Heim R and others (2002) The Drought Monitor. Bull Am Meteorol Soc 83: 1181-1189

Svoboda MD, Fuchs BA, Poulsen CC, Nothwehr JR (2015) The drought risk atlas: enhancing decision support for drought risk management in the United States. J Hydrol (Amst) 526:274-286

Wilhite DA, Buchanan-Smith M (2005) Drought as hazard: understanding the natural and social context. In: Wilhite D (ed) Drought and water crises: science, technology, and management issues. CRC Press, Boca Raton, FL, p 3-29

Wilhite DA, Botterill L, Monnik K (2005) National drought policy: lessons learned from Australia, South Africa, and the United States. In: Wilhite D (ed) Drought and water crises: science, technology, and management issues. CRC Press, Boca Raton, FL, p 137-172

Wilhite DA, Sivakumar MVK, Pulwarty R (2014) Managing drought risk in a changing climate: the role of national drought policy. Weather Clim Extrem 3:4-13

Woodhouse CA, Overpeck JT (1998) 2000 years of drought variability in the central United States. Bull Am Meteorol Soc 79:2693-2714

World Economic Forum (WEF) (2014) Global Risks 2014, 9th edn. World Economic Forum, Geneva. http://www3. weforum.org/docs/WEF_GlobalRisks_Report_2014.pdf

Zhao T, Dai A (2015) The magnitude and causes of global drought changes in the twenty-first century under a low-moderate emissions scenario. J Clim 28:4490-4512

Submitted: January 4, 2016; Accepted: May 24, 2016

Proofs received from author(s): August 17, 2016 